\title{
Requirements for web-based integrated management systems in the production of image processing components
}

Philipp Greiner, Tania Bogatsch, Norbert Jahn, Laurin Martins, Gerhard Linß, et al.

Philipp Greiner, Tania Bogatsch, Norbert Jahn, Laurin Martins, Gerhard Linß, Gunther Notni, "Requirements for web-based integrated management systems in the production of image processing components," Proc. SPIE 11144, Photonics and Education in Measurement Science 2019, 111441D (17 September 2019); doi: 10.1117/12.2532572

SPIE Event: Joint TC1 - TC2 International Symposium on Photonics and Education in Measurement Science 2019, 2019, Jena, Germany 


\title{
Requirements for web-based, integrated Management Systems in the Production of Image Processing Components
}

\author{
Philipp Greiner ${ }^{\mathrm{a}}$, Tania Bogatsch ${ }^{\mathrm{b}}$, Norbert Jahn ${ }^{\mathrm{a}}$, Laurin Martins ${ }^{\mathrm{a}}$, Gerhard Linß ${ }^{\mathrm{a}}$, and \\ Gunther Notni ${ }^{\mathrm{b}}$ \\ ${ }^{a}$ SQB GmbH, Werner-von-Siemens-Str. 9, 98693 Ilmenau, Germany \\ ${ }^{b}$ TU Ilmenau, Fakultät für Maschinenbau, Fachgebiet Qualitätssicherung und Industrielle \\ Bildverarbeitung, Gustav-Kirchhoff-Platz 2, 98693 Ilmenau, Germany
}

\begin{abstract}
New and revised standards are increasing the demands placed on management systems. The aim of this paper is to investigate how the effort required to create and maintain management systems can be minimized. A concept is presented, which also considers the integration of different management systems. First the existing management systems are evaluated. Then the requirements from practice are determined. These are examined and evaluated. Based on both results it is determined which requirements an integrated management system must fulfil. On this basis, a practical concept of an integrated management system is developed. As well optimal interfaces are considered. This concept is transferred into a web-based application. In order to ensure an optimal implementation and expandability, the structure is realized modularly.
\end{abstract}

Keywords: Management systems, quality management, web application, Google Go, HTML, standards, highlevel structure, integrated management systems

\section{INTRODUCTION}

The ever-increasing complexity of processes and documentation as well as the higher requirements of standards place high demands on management systems. By combining several management systems into one integrated management system, several sectors can be covered. Software-based integrated management systems serve to systematize the requirements.

\section{INTEGRATED MANAGEMENT SYSTEMS}

According to ISO 9000:2015, a management system is a "set of interrelated or interdependent elements of an organisation to define policies, objectives and processes to achieve these objectives". ${ }^{1}$

Examples of a management system are: quality, environmental and occupational health and safety management system.

For many companies, not only one management system is relevant, but they also have to meet the requirements of several management systems. An isolated consideration of the individual management systems cannot be regarded as an optimal solution. An integration of the management systems relevant for the organisation offers advantages and therefore is to be preferred. ${ }^{2}$

Further author information:

Philipp Greiner: E-mail: philipp.greiner@quick-image.de, Telephone: +49 15140424443

Website: www.quick-image.de

Photonics and Education in Measurement Science 2019, edited by Maik Rosenberger,

Paul-Gerald Dittrich, Bernhard Zagar, Proc. of SPIE Vol. 11144, 111441D

(C) 2019 SPIE · CCC code: 0277-786X/19/\$21 - doi: 10.1117/12.2532572

Proc. of SPIE Vol. 11144 111441D-1 
Integrated management systems offer the following advantages: ${ }^{2}$

- cost and time savings by avoiding duplication of work,

- use of synergy effects,

- reduction of the amount of documented information,

- reduced maintenance of the system and

- improve acceptance of the system by the employees.

\subsection{ISO 9001:2015 as guiding standard}

The standard ISO 9001:2015 defines requirements for quality management systems. It came into force in September 2015. This standard is published by the International Organization for Standardization (ISO), which is an association of national standards organizations. The Technical Committees of the International Organization for Standardization are responsible for the preparation of this standard.

\subsection{High-Level Structure}

In order to make optimum use of the advantages of an integrated management system, the high-level structure was developed as part of the preparation of the standard ISO 9001:2015. This is a superordinate structure which is oriented towards the PDCA cycle - also known as the Deming Circle (see figure 1). The first three chapters (Scope, Normative References as well as Terms and Definitions) serve as an introduction. Chapters four to six are assigned to the Plan in the PDCA cycle. Chapters seven and eight reflect the Do. Chapter nine refers to the Check and chapter ten to Act. Figure 2 illustrates where the outline points of the high-level structure can be found in the PDCA cycle.
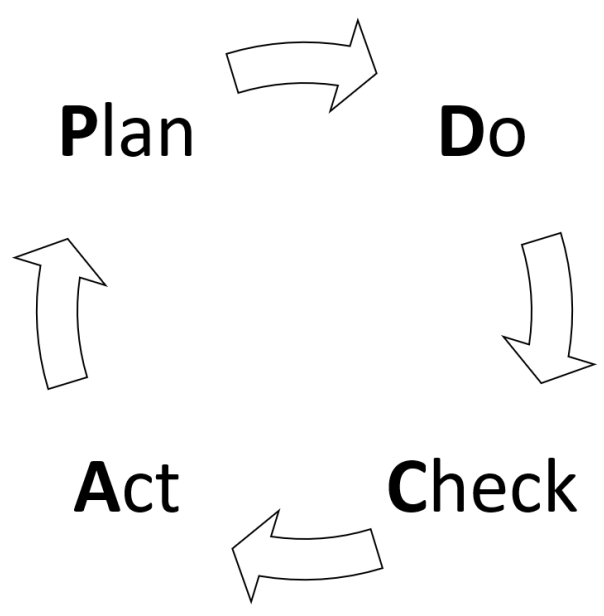

Figure 1. PDCA cycle

The high-level structure not only structures the ISO 9001:2015, but also forms a uniform structure for other standards - such as the environmental management system standard ISO 14001:2015. As part of the regular revision of standards, more and more standards are being converted to this overarching structure. Synergy effects during integration can be realized by adapting the structure of several standards to each other. ${ }^{3,4}$ 


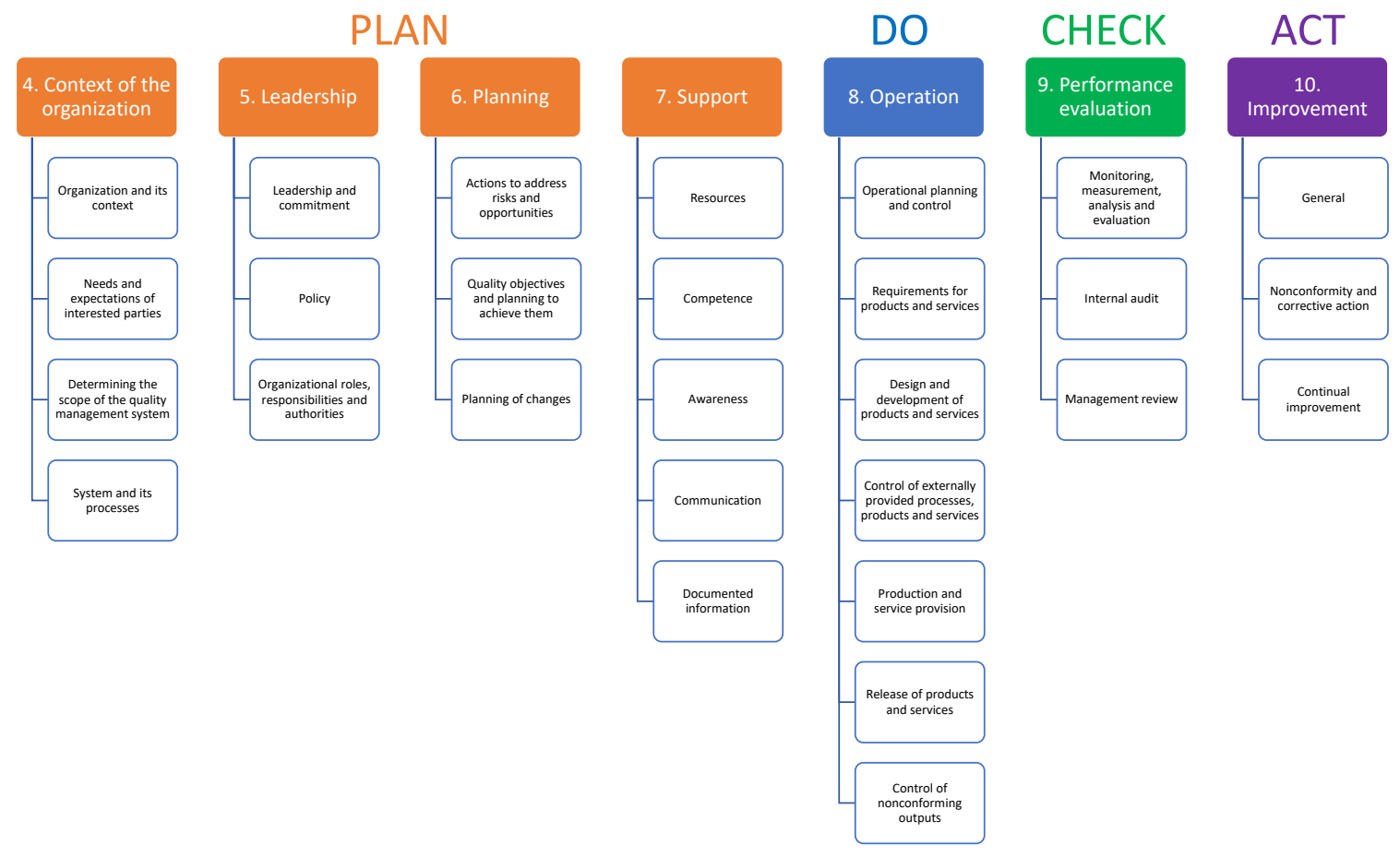

Figure 2. PDCA cycle with the High Level Structure

\subsection{Requirements for integrated management systems}

Widely used standards such as the quality management standard ISO 9001:2015, the environmental management standard ISO 14001:2015 and the occupational safety and health management standard ISO 45001:2018 require documented information as proof that the requirements of the standard are met.

The ISO 9001:2015 serves many standards as a guideline or represents an extension to ISO 9001:2015, the documented information required in the standard are also necessary in other standards, such as the IATF 16949. Due to the high-level structure some requirements overlap also from standards of different sectors. The standard requirements for integrated management systems are therefore not the sum of all the requirements considered individually, but are lower due to overlaps and synergy effects.

Table 1: Required documented information of the standard ISO 9001:2015

\begin{tabular}{|l|l|}
\hline Chapter & Documented Information \\
\hline 4.3 & Scope of the organization's quality management system \\
\hline 4.4 & For the (scheduled) execution of the processes of the organization \\
\hline 5.2 .2 & Quality policy \\
\hline 6.2 & Quality objectives \\
\hline 7.1 .5 .1 & Fitness for purpose of the monitoring and measurement resources. \\
\hline 7.1 .5 .2 & Measurement traceability \\
\hline 7.2 & Evidence of competence \\
\hline 8.1 & $\begin{array}{l}\text { On the suitability of the processes and proof of conformity of products and } \\
\text { services with their requirements }\end{array}$ \\
\hline
\end{tabular}




\begin{tabular}{|l|l|}
\hline 8.2 .3 & Review of the requirements for products and services \\
\hline 8.2 .4 & Changes to requirements for products and services \\
\hline 8.3 .2 & Design and development planning \\
\hline 8.3 .3 & Design and development inputs \\
\hline 8.3 .4 & Design and development controls \\
\hline 8.3 .5 & Design and development outputs \\
\hline 8.3 .6 & Design and development changes \\
\hline 8.4 .1 & Supplier evaluation \\
\hline 8.5 .2 & Identification and traceability \\
\hline 8.5 .3 & Property belonging to customers \\
\hline 8.5 .6 & Control of changes \\
\hline 8.6 & Release of products and servicesn \\
\hline 8.7 .2 & Control of nonconforming outputs \\
\hline 9.1 .1 & Monitoring, measurement, analysis and evaluation \\
\hline 9.2 & Audit programs \\
\hline 9.2 & Audit results \\
\hline 9.3 & Management review \\
\hline 10.2 .2 & Nonconformity and corrective action \\
\hline
\end{tabular}

\section{STATE OF THE ART OF SOFTWARE-BASED MANAGEMENT SYSTEMS}

In this chapter common (software-based) management systems are compared. Common systems and systems with special features - such as a automatic document matrix - are listed.

Almost all software-based management systems have a modular structure. Thus the programs can be adapted to the needs of the enterprises. The majority also relies on web-based access to the management system. The program and the data are either stored on local servers or are cloud-based. A modular structure and web-based access can thus be regarded as standard for management systems.

Not all, but some management systems have a full text search. This allows the entire content of all documents of the management system - and not only individual files or file formats - to be scanned. Resulting in a far more efficient and faster search for relevant information.

The management systems sycat IMS Portal and CAQ.Net Management System offer automatic versioning. Processes and documents are automatically provided with a version status by a versioning system. With the sycat IMS Portal all changes can be traced back at any time. The CAQ.Net management system stores older versions on a document server. The CWA SmartProcess management system even contains a graphical version comparison in order to provide full visualisation of changes.

The management systems Babtec.Q and ConSense IMS offer automatic archiving. Older documents are automatically stored in the archive. Several management systems offer a simple, integrated archiving process in order to provide full access to all versions.

The QS-1-2-3-4 management system offers voice input. Voice input can be used to easily enter measurement results, among other things. In addition to the QS-1-2-3-4 management system, the CAQ.Net management system also includes barcode input. This is particularly suitable for incoming and outgoing goods. This allows products to be booked in and out of the system quickly and easily.

The handling of the allocation of read and write rights was different for the individual systems. A rudimentary definition of access and read authorization is implemented in all systems. The access to documents can be set for individual persons or user groups. Thus it can be regulated that only those employees see the documents 
and processes that concern them. This means that even documents that are not to be viewed by all employees can only be released for certain persons or departments (e.g. management, personnel). The systems Q.wiki and CWA SmartProcess offer more comprehensive settings. With these systems, in addition to assigning read rights, individual write and edit rights can also be set.

There are also differences in (graphical) design options of the individual systems. For a uniform corporate design of the systems in the context of corporate identity, some systems offer possibilities for adaptation. This type of customizing mainly refers to the company logo and adaptation of colors. Some systems offer the possibility to customize the start page individually. For example, the latest updates and important documents for the user can be displayed. Some systems allow you to make settings in the masks. Fields can be removed or added. You can also change the names of the fields.

Within the modular structure of almost all management systems, these can be extended with various applications. Depending on the system, different extensions are available. Frequently selectable components are: audit managers, process managers, project managers, complaint managers and test equipment management. Special extensions that are only offered by individual systems are: Training Manager (IMS Premium), Data Protection Manager (ConSense IMS), Warranty Manager (Babtec.Q), Knowledge Manager (ConSense IMS).

Interfaces are available with the software-based management systems mainly for the Microsoft Office programs. Many systems also offer interfaces to ERP systems* and SAP. Some systems also support Microsoft Sharepoint. ConSense IMS also offers an interface to OpenOffice.

From a technical point of view all presented systems support a setup of the software via company servers. No installation on the client PCs is necessary. The software is only installed on the company server. All data and documents are also stored on these servers. Some manufacturers also offer the management system as $\mathrm{SaaS}^{\dagger}$ in the cloud. With this option, no software has to be installed on company servers or client PCs. The client PCs gain access via Internet to the servers of the provider on which the software is installed. All data and documents are also stored on the provider's servers.

All providers of the management systems presented here also offer other services. In addition to the obligatory installation of the management system and training courses, some also offer comprehensive advice on quality management.

One system that stands out from the others is Q.wiki from the company Modell Aachen GmbH. The special feature is that the management system functions according to the Wiki principle. This means that all employees can participate in the creation and processing of documents, descriptions and processes. That means for example not only the quality management representative can work on descriptions of processes or workflows, but also the coworkers, who accomplish this daily, can edit this. However, to ensure that no incorrect information is written, the change undergoes a release process to ensure accuracy. According to the provider, this high degree of employee interaction freedom means that the system should have a higher number of employee accesses than other management systems. It is questionable, however, whether the interest of the employees remains so high over a longer period of time, or only in the initial phase, when it is new for everyone and the employees try out the system.

Another system that stands out from the mass of management systems is the sycat IMS Portal from sycat IMS GmbH. With this solution, the focus is on the graphical representation. As little text as possible should be used. Thus an environment is to be created in which every employee can find his way quickly.

\section{WEB-BASED, INTEGRATED MANAGEMENT SYSTEMS}

According to the investigation of current software-based management systems, the state of the art is that a software-based management system has a modular structure. Furthermore, it is standard that access to the management system is web-based. A requirement that is not yet standard for all systems, but is widespread, is a full text search.

\footnotetext{
*ERP stands for Enterprise Resource Planning.

${ }^{\dagger}$ SaaS stands for Software as a Service.
} 
One of the most important functions of an integrated management system is the document management system. This should not only possess the already established functions, but also offer further simplifications and improvements for the users. One such is the implementation of automatic versioning. This function facilitates the administration of the documents considerably. An automatic archiving - which automatically stores older versions of documents in the archive - is also a function that facilitates the administration of documents.

Document management systems manage large amounts of documents and information. These should not always be editable and viewable by every user. To ensure this, it makes sense to assign authorizations with user roles. The setting of far-reaching processing and reading authorizations not only ensures a controlled flow of information, but also ensures that only those documents can be processed which are also responsible for it.

The following is state of the art for document management systems:

- modular construction and

- full-text search.

The following is implemented in a few systems:

- automatic versioning,

- automatic archiving,

- permissions and

- document matrix.

The listed functions are available on the market in various solutions. However, no solution combines all functions. Systems currently available on the market are not optimally tailored to the needs of users. For a new system the following features have to be considered:

- intuitive and self-explanatory operation,

- no overcrowded system,

- extensive customer-specific adjustment possibilities,

- automation where possible (to reduce maintenance effort),

- integration of documents from different standards and

- systematization of document filing, covering different standards.

For the development of a new document management system all listed characteristics and functions are combined in one system. Particular attention is paid to user-friendliness. Through self-explanatory links, a tidy workspace and a familiar design, users should quickly find their way around.

\section{Automatic versioning/archiving}

The upload of new documents is only permitted for authorized persons. The uploaded document is automatically assigned the version number 1.0. If the uploaded document is a Word file, the system automatically generates and saves a PDF file. Thus, users who do not have permission to edit the document will be displayed as a PDF file. This is opened directly in the browser window and cannot be edited.

To edit documents, the latest version must first be downloaded from the system as an editable file. The editing of the content takes place with the help of a suitable program (e.g. text editing program). After all changes to the content have been made, the document is saved with the same name. Click on the upload button 
in the context menu to open a window with several setting options. First, the new version of the document must be selected for uploading. A new version number is proposed based on the version number of the previous document.

For better traceability of the changes, it is possible to enter a comment. The system automatically adds the date and time at which the edited version was uploaded and the processor to this information. Clicking the update button loads the new version into the system. If a version of the document with PDF already exists, the PDF will be overwritten to reflect the latest version. When the documents are updated, the older versions are automatically archived. The previous version is moved to the archive folder. If this is not yet available in the respective folder, one will be created. Documents in the archive folder are not displayed in the document management system. This ensures that only the latest versions are visible. To ensure that the overview is not lost even with several previous versions in the archive folder, the documents are coded according to the respective version.

\section{Document matrix}

Some standards require a document matrix. But even so, a systematic overview of all relevant documented information makes sense. This enables them to be found more quickly. Furthermore, the current version of a document is visible at a glance. The document matrix contains the following information:

- name of the document,

- author,

- function of the author,

- date of revision,

- storage location,

- version status,

- file type and

- comment on the update.

Maintaining a document matrix manually is very time-consuming and error-prone. As soon as a document that has also been included in the document matrix is changed, this must also be updated in the matrix. If this does not happen, the version in the document matrix and the most current version differ from each other.

To prevent this from happening, the web-based integrated management system contains an automatic document matrix. As soon as a new version of a document is uploaded to the system, the user can add a comment about the update. The editor, date and version are added automatically. The version can also be changed manually by the editor. The entry in the document matrix is also automatically updated after confirmation of the entries by the editor. This prevents the information in the matrix from being out of date.

\section{WEB-BASED TECHNOLOGIES FOR INTEGRATED MANAGEMENT SYSTEMS}

In web development, software can be divided in two layers: front-end and back-end. The front-end gives a possibility for user to interact and visualize the data of the back-end. It is responsible for the user interface - for example, user interface and data exchange. The data itself is stored on the back-end, for example, on the servers. Almost all programming languages can be used for the back-end. However, not all languages are suitable for the front-end.

HTML (Hypertext Markup Language) is the main technology of the front-end of web-based applications. CSS (Cascading Style Sheets) is a stylesheet language, which is also responsible for the visual representation of the content. 
For back-end it is better to choose a suitable programming language according to the special application. Languages like $\mathrm{C}++$, Python and Java are widely used ${ }^{\ddagger}$. However, depending on the application, more modern languages such as Google Go may also be suitable. In the case of languages that have only been developed in recent years, more attention could be paid to the requirements of the current time. With older programming languages, new features are regularly implemented, but these also carry a lot of legacy with them. Modern functions for development are often not available.

\section{CONCLUSION AND FUTURE WORK}

This paper has presented an overview of software-based integrated management systems and their functions. Much attention must be paid to the development of easy-to-use, web-based, integrated management systems. Features such as automatic versioning/archiving and the automatic document matrix support companies in

managing their management systems. It should become easy for the employees to view relevant documents. Thus the information policy in the enterprise can be improved.

\section{REFERENCES}

[1] Standard, ISO 9000:2015: Quality management systems - Fundamentals and vocabulary, International Organization for Standardization, 2015.

[2] G. Linß, Qualitätsmanagement für Ingenieure, Carl Hansa Verlag, Munich, 2018 (fourth edition).

[3] Standard, ISO 9001:2015: Quality management systems: Requirements, International Organization for Standardization, 2015.

[4] W. E. Deming, Out of the crisis., Massachusetts Institute of Technology, Cambridge, 1994 (nineteenth edition).

[5] TIOBE, "Tiobe index." Overleaf https://www.tiobe.com/tiobe-index/. (Accessed: 18 April 2019).

\footnotetext{
${ }^{\ddagger}$ see TIOBE Index. ${ }^{5}$
} 